\title{
Development of Analytical Parameters for a Hepatoprotective Polyherbal Formulation-Liverem
}

\author{
Jayachandra Kuncha1*, P Thirugnanasambantham², T Muthukumaran ${ }^{3}$, N Narayanan4, Siva Siddharth ${ }^{5}$ \\ ${ }^{1}$ Research Scholar, Department of Biotechnology, Periyar Maniammai University, Thanjavur - 613 403, Tamil Nadu, India \\ ${ }^{2} \mathrm{Head}, \mathrm{R} \& D$ Centre, Rumi Herbals Pvt Ltd., Chennai, India \\ ${ }^{3}$ Assistant Professor, Department of Biotechnology, Periyar Maniammai University, Thanjavur - 613 403, Tamil Nadu, India \\ ${ }^{4}$ Director, Department of Pharmaceutics, Jaya college of Pharmacy, Chennai, India \\ ${ }^{5}$ Director, Rumi Herbals Pvt Ltd., Chennai, India
}

Received: August 25, 2015; Accepted: September 14, 2015; Published: October 01, 2015

*Corresponding author: Jayachandra Kuncha, Research Scholar, Department of Biotechnology, Periyar Maniammai University, Periyar Nagar, vallam, Thanjavur - 613 403, Tamil Nadu, India, Tel: +7401486335; E-mail: jayachandrakuncha@gmail.com

\begin{abstract}
Developing analytical parameters for traditional system of medicines are a crucial step in establishing the quality of herbal products, presence of phytochemical ingredients and its therapeutic efficacy. Globally WHO and Nationally AYUSH both specify and encourage doing quality analysis of herbal raw materials and finished products which ensure quality and safety. In this research work, a hepatoprotective polyherbal ayurvedic formulation Liverem has been taken to establish its quality by using various organoleptic and physicochemical parameters specified by Ayurvedic and Siddha pharmacopeias. The results revealed that all the specified parameters found to be within the limits.
\end{abstract}

Keywords: Analytical Parameters; Polyherbal Formulation; Hepatoprotective; Physicochemical Parameters

\section{Introduction}

The quality control of herbal crude drugs and formulations is important to justify their acceptability in modern system of medicine [1]. Polyherbal formulations, which have widespread acceptability as therapeutic agents include anti-diabetic, lipid lowering and hepatoprotective agents [2]. Now-a-days, in the whole world there is turn to return towards the use of herbal products and to adopt more natural way of life. People prefer natural food, herbal medicines and natural curing practices for healthy life. Use of natural remedies for the treatment of liver diseases has a long history, starting with the ayurvedic treatment and extending to the Chinese, European and other systems of traditional medicines. In spite of the tremendous advances made, no significant and safe hepatoprotective agents are available in modern therapeutics. Therefore, importance has been given globally to develop plant based hepatoprotective drugs effective against a variety of liver disorders [3].

Even though herbal medicines are become popular and effective in the treatment of several ailments, they are still unacceptable in the treatment modalities due to (i) lack of standardization (ii) lack of identification of active ingredient(s) / principle(s) (iii) lack of randomized controlled clinical trials (RCTs) and (iv) Lack of toxicological evaluation. Standardization refers to the body of information and controls, necessary to produce materials of reasonable consistency. This is achieved through minimizing the inherent variation of natural product composition through quality assurance practices applied to agriculture and manufacturing process [4].

Standardization is an important aspect for maintaining and assessing the quality and safety of the polyherbal formulation as combinations of more than one herb to attain the desire therapeutic effect [5]. Standardization minimizes batch to batch variation; assure safety, efficacy, quality and acceptability of the polyherbal formulations [6]. Around globe all countries insisting to do standardization of herbal products by using standard protocols. During this process we can check the quality of product as well as screen the safety parameters such as microbial and heavy metal limit tests, which are play major health concern for the utilization of herbal products.

As a part of research work, a marketed hepatoprotective polyherbal ayurvedic formulation 'Liverem' has been taken to establish its quality by using various organoleptic and physicochemical parameters specified by Ayurvedic [7], Siddha pharmacopeia [8] and WHO [9] guidelines. The herbal ingredients which are used for the formulation has claim that it posses potent hepatoprotective activity. The formulation is manufactured by Rumi Herbals Pvt. Ltd., a GMP certified, and 20 years old company and is marketed by Rohini Global Marketing Pvt Ltd. Chennai.

\section{Materials and Methods}

\section{Plant materials}

Phyllanthus amarus (Whole plant), Azadirachta indica (Leaves), Picrorhiza kurroa (Rhizomes), Eclipta alba (Whole plant) and Swertia chirayita (Stem and leaves) were procured 
from local herbal vendors in Chennai with individual quality control report.

\section{Physical examination}

All the dry plant materials were examined physically by spreading in polythene sheet, cleaning was done by experienced people.

\section{Grinding and sieving}

The plant materials were ground into coarse powder with the help of electric grinder. Sieving was done to get uniform granules by using sieve No.40.

\section{Raw material quality assessment}

The below mentioned parameters were assessed as per the standards provided by Ayurvedic and Siddha pharmacopeia, Govt. of India.

Foreign matters: Foreign matter is the material which contain other plant parts, mineral or mud, sand admixtures, products of organism and other than the named material. $100 \mathrm{~g}$ of the drug sample to be examined was weighed and spread out as a thin layer; the foreign matter was detected by inspection with the unaided eye or by the use of a lens (6x). It was separated, weighed and the percentage of foreign matters present was calculated.

Total ash: The residue remaining after incineration is the ash content of a dry plant material. It is the measure of the total amount of material remaining after incineration. An electric muffle furnace, capable of maintaining a temperature of $625 \pm 25$ ${ }^{\circ} \mathrm{C}$ was used for measuring ash content.

The Ash content $(\%)=(C-A) /(B-A) X 100$.

Where: $A$ = weight of empty crucible (g), $B=$ weight of crucible and sample (g), C = weight after ashing (g)

Acid insoluble ash: It is the residue obtained after boiling the total ash with dilute $\mathrm{HCl}$ and igniting the remaining insoluble matter. This measures the amount of silica present, especially as sand and siliceous earth. The ash obtained was boiled for 5 min with $25 \mathrm{ml}$ of dilute $\mathrm{HCl}$, the insoluble matter was collected in an ash-less filter paper, washed with hot water and ignited to constant weight. The percentage of acid-insoluble ash was calculated.

Water soluble extractive: $5 \mathrm{~g}$ of the air dried drug was macerated, coarsely powdered, soak with $100 \mathrm{ml}$ of water in a flask for $24 \mathrm{~h}$, shaking frequently during $6 \mathrm{~h}$ and allowed to standing for $18 \mathrm{~h}$. Take $25 \mathrm{ml}$ of the filtrate, evaporated to dryness in a tarred flat bottomed shallow dish and dried at $105^{\circ} \mathrm{C}$ to constant weight and weighed. The percentage of water-soluble extractive with reference to the air-dried drug was calculated.

Alcohol soluble extractive: $5 \mathrm{~g}$ of the air dried drug was macerated, coarsely powdered, soak with $100 \mathrm{ml}$ of Alcohol of the specified strength in a closed flask for $24 \mathrm{~h}$, shaking frequently during $6 \mathrm{~h}$ and was allowed to stand for $18 \mathrm{~h}$. Rapidly filtered, taking precautions against loss of solvent, evaporated $25 \mathrm{ml}$ of the filtrate to dryness in a tarred flat bottomed shallow dish, and dry at $105^{\circ} \mathrm{C}$, to constant weight and weigh. The percentage of alcohol-soluble extractive with reference to the air-dried drug was calculated.

Loss on Drying or Moisture content: It is the amount of water or volatile content present in the sample. Plant material may get spoiled (microbial attack) if more moisture present. The plant materials were weighed, kept in an oven at $105^{\circ} \mathrm{C}$ and equilibrated. It was reweighed till three constant readings.

\section{Microbial safety profile}

All the raw materials must be free from microbial contamination. It is the major safety parameter to ensure the product quality. Microbial screening was carried out to estimate the number of viable microorganism present in the material. Various differential and selective medias are utilized for screening microbial contamination. For Total viable count (Casein soya bean digest agar), Total yeast and moulds (Sabouraud dextrose agar with antibiotics), E. coli (MacConkey agar and EMB agar), Salmonella (Brilliant Green agar) Staphylococcus sp. (Mannitol salt agar) Pseudomonas aeruginosa, (Cetrimide agar) were used to screen the organisms as per the AYUSH guidelines.

\section{Pre-formulation studies}

The below mentioned parameters were assessed as per the standards provided by Protocols for testing Ayurvedic, Siddha and Unani Medicines, Dept. of AYUSH, Govt. of India [10].

Organoleptic characters: Texture, Color, Odor and taste were assessed by using sensory organs

pH: Individually, 5\% solution was made and the $\mathrm{pH}$ was checked by using digital $\mathrm{pH}$ meter

Microscopic Characteristics: The powdered materials were spread as thin film on glass slide and observe shape of the granules under the microscope.

Observations under UV light: The materials were mixed with $10 \% \mathrm{NaOH}$ and $5 \% \mathrm{HCl}$ and observe under UV light at 254 $\mathrm{nm}$ and also observe without adding above constituents.

Flow Properties: Flow properties of drug indicate the uniformity of the granules and it is useful for proper filling and clinical application. The following methods are used to evaluate the flow properties.

Angle of repose: Angle of repose is characteristic related to interparticulate friction or resistance to movement between particles [11]. A funnel was fixed at a particular height on a burette stand. A white paper was placed below the funnel on the table. The powdered drug $(5 \mathrm{~g})$ passed slowly through the funnel until it forms a pile. The radius of the pile was noted down. Angle of repose of the powder material was calculated by using the formula: $\tan \theta=h / r ; \theta=\tan (h / r)$ where, $h=$ height of the pile, $r$ $=$ radius.

Bulk density (DO): $25 \mathrm{~g}$ of accurately weighed powder was poured into a graduated cylinder, powder bed was made uniform 
without disturbing the cylinder and the volume was measured directly from the graduation mark on the cylinder as $\mathrm{ml}$ [12]. The volume measure was called as bulk volume and bulk density is calculated as Bulk density $=\frac{\text { weight of the powder }}{\text { Bulk volume }}$

Tapped density (Df): After measuring D0, same cylinder was set to measure tapped density. The cylinder was tapped with 100 tap drop/minute and operated for 500 taps. Volume was noted as Va, tapping was done again for 750 times and final volume was noted as $\mathrm{Vb}$. The difference between $\mathrm{Va}$ and $\mathrm{Vb}$ was calculated and when it was found to be not more than $2 \%$, then Vb was considered as final tapped volume and tapped density was calculated using the following formula $=\frac{\text { weight of the powder }}{\text { Tapped volume }}$

Compressibility indices: The bulk and tapped densities were used to calculate the compressibility indices (Carr's index and Hausner ratio) which provide the flow properties and compressibility of powders.

The Hausner's ratio is a number that is correlated to the flow ability of a powder or granular material.

$$
\text { Hausner ratio }=\frac{\text { Tapped density }}{\text { Bulk density }}
$$

Carr's index depends upon the bulk density and tapped density of a powder and evaluates the rate at which it is packed down. The following formula was used for the determination of Carr's Index.

$$
\text { Carr's index }=\frac{\text { Tapped density-Bulk density }}{\text { Tapped density }} \text { X } 100
$$

\section{Quality control parameters}

Composition and Preparation of Capsule: Each $100 \mathrm{mg}$ of earlier mentioned plant powder materials were mixed properly by using butterfly mixture and made $500 \mathrm{mg}$ of polyherbal hard gelatin capsule (Zero size) by using semi automated capsule filling machine.

Organoleptic characters: Texture, color, odor, taste and uniformity were determined by sensory organs.

pH: After preparing $5 \%$ solution of the finished product, the $\mathrm{pH}$ was checked by using digital $\mathrm{pH}$ meter.

Flow properties: For the finished product flow properties like Angle of repose, Bulk density, Tapped density, Carr`s index and Hausner ratio were assessed by standard methods.

Weight variation test: Test for uniformity of weight was performed as per Indian Pharmacopeia (IP), 2007 [13]. Randomly selected 20 capsules were weighed (individually and together) in a single pan balance. The average weight, variation in the individual capsule and the standard deviation was calculated.

$$
\text { Weight variation }=\frac{\text { Weight of capsule-Average weight }}{\text { Average weight of capsule }} \times 100
$$

Drug content uniformity test: Test for drug content

uniformity was carried out as per Indian Pharmacopeia, 2007. 20 capsules were taken and emptied their content in a mortar and pestle and ground into a fine powder. From this, 500mg of powder was taken into a volumetric flask and diluted with phosphate buffer (pH 6.8). The absorbance of the solution was measured at $213 \mathrm{~nm}$ by using UV-Visible spectrophotometer (Systronics, UV-Vis Spectrophotometer) [14].

Disintegration: This test is useful as a quality assurance tool for conventional dosage forms. The efficacy of a drug can be dependent on the rate at which the capsule disintegrates in the patient's gastrointestinal tract. The disintegration test is a measure of the time required under a given set of conditions for 6 randomly selected capsules to disintegrate into particles which will pass through a 10 mesh screen with in a disintegration assembly at maintained temperature $37 \pm 2^{\circ} \mathrm{C}$. Disintegration test was performed using the disintegration test apparatus [15].

\section{Microbial analysis}

Microbial analysis was carried for capsule as per procedures of Indian Pharmacopeia 2007 and WHO Guideline. The test included total bacterial count, total yeast and mould count, Identification of specified organisms such as Escherichia coli, Salmonella sp., Staphylococcus aureus and Pseudomonas aeruginosa.

\section{Test for heavy metals}

Preparation of samples by acid digestion method: Accurately weighed $2 \mathrm{~g}$ of sample was taken in Kjeldahl flask. Acid mixture of Nitric acid Perchloric acid (4:1) was added in the flask and heated continuously till the solution became colourless. The sample was then transferred to a $25 \mathrm{ml}$ volumetric flask and the volume was made-up with distilled water. Reagent blank was synchronously prepared according to the above procedure. The standards of Lead, Cadmium, Arsenic and Mercury were prepared as per the protocol in the manual. The samples were analyzed for the presence of $\mathrm{Pb}, \mathrm{Cd}$, As and $\mathrm{Hg}$ using Atomic Absorbance Spectrophotometer (AAS) (SHIMADZU).

\section{Results and Discussion}

Standardization is a system ensuring predefined set of the quality and therapeutic effect of the constituents in each dose [16]. Various types of herbal medicines have been used as curative agents in different parts of the world [17]. Drugs derived from herbs may have possible therapeutic relevance in the treatment of illness [18]. The polyherbal formulation was formulated for hepatoprotective activity by using traditional medicinal plants. In the earlier research work, the formulation was screened for hepatoprotective activity in pre-clinical model. The results showed excellent hepatoprotective activity by $\mathrm{CCl}_{4}$ induced hepatic damage [19] and also the formulation was prescribed by Ayurvedic and Siddha Physicians for several liver diseases. In the present study, Liverem has been taken for the development of quality control parameters as per Ayurvedic, Siddha, and Indian Pharmacopeia's, followed by AYUSH and WHO guidelines. 


\section{Determination of raw materials Identity and Purity}

Selected medicinal plants for formulation were screened individually for its identity and purity, the given specifications found within the limits (Table 1). Ash contents were below the given value which indicates the less contamination. Moisture content was found to be less than $5 \%$ which is a good indicator for less susceptibility for microbial contamination. Table 1 show the microbial limits of individual raw material which indicates within limits. This shows the cleanliness of raw material and good storage practice in the manufacturing premises.

\section{Pre-formulation studies}

Pre-formulation parameters like organoleptic, microscopic, $\mathrm{pH}$ and flow properties such as bulk density, tap density, Carr's index, Hausner ratio and angle of repose were carried out for the selected individual raw materials (Table 2).

\section{Quality control parameters for the finished product}

In the case of herbal drugs, capsule is the convenient form for oral administration, better acceptance and reduces esophageal irritation. The capsule was evaluated by different Pharmacopeial and non-Pharmacopeial physicochemical tests such as organoleptic characters, $\mathrm{pH}$, flow properties, weight variation, moisture analysis, drug content uniformity and disintegration. 3 consecutive batches were tested and the average values were taken.

The $\mathrm{pH}$ of $5 \% \mathrm{w} / \mathrm{v}$ solution was 6.72 which indicate suitability for human use. Other Physicochemical properties of the finished product were also carried out (Table 3). The Indian Pharmacopeia limit for weight variation in case of capsule weighting more than $300 \mathrm{mg}$ is $\pm 5 \%$. The results showed weight variation of the Liverem capsule found to be within the IP limit. The moisture content was less than $5 \%$, the drug content uniformity also found within IP limit. The disintegration time was found to be an average of $240.16 \mathrm{sec}$, which means capsule will get disintegrated in the stomach within a short span of time when taken orally. Bulk density, Tapped density, Hausner ratio, Carr`s index and angle of repose were found to be $0.95 \mathrm{~g} / \mathrm{cm}^{3}$, $1.03 \mathrm{~g} / \mathrm{cm}^{3}, 1.08,8.07$ and $32.83^{\circ}$ (Table 4). Value for Carr's index below 15 indicates excellent flowing material and value over 20-30 suggests poor flowing material. Values for angle of repose less than $30^{\circ}$ usually indicates a free flowing material and angle greater than $40^{\circ}$ suggest a poor flowing material [20].

The microbiological and heavy metal profile of the formulation were given in Table 5. The total aerobic, yeast and mould count was $100 \mathrm{cfu} / \mathrm{g}$ and $10 \mathrm{cfu} / \mathrm{g}$ respectively and Escherichia coli, Salmonella sp., Staphylococcus aureus Pseudomonas aeruginosa were absent in the formulation. Heavy metal contamination is the foremost concern in traditional system of medicine as they are found to be toxic if their level in the body surpasses the respective maximum permitted limits [21].

Among highly toxic environmental pollutants lead is one of the components. When human body exposed to lead it can form complexes with biomolecules and affects neuromuscular, cardiovascular, reproductive and gastrointestinal systems. The organs like liver and kidney severely damaged by lead [22,23]. As per Government of India, AYUSH guidelines permissible limits in Ayurveda, siddha and unani products are less than $10 \mathrm{ppm}$. High levels of cadmium causes damage to the liver and majorly to the kidney due to very slow excretion and it accumulated in this organ and causes irreversible damage to renal tract. It also shows deleterious effect on other organs when exposed to high levels of

Table 1: Individual raw material specifications as per Ayurvedic and Siddha pharmacopeias.

\begin{tabular}{|c|c|c|c|c|c|c|c|c|c|c|c|}
\hline \multirow{2}{*}{ S.No } & \multirow{2}{*}{ Specification } & \multicolumn{2}{|c|}{ Phyllanthus amarus } & \multicolumn{2}{|c|}{ Picrorhiza kurroa } & \multicolumn{2}{|c|}{ Eclipta alba } & \multicolumn{2}{|c|}{ Azadirachta indica } & \multicolumn{2}{|c|}{ Swertia chirayita } \\
\hline & & API (\%) & Result & API (\%) & Result & API (\%) & Result & API (\%) & Result & API (\%) & Result \\
\hline 1 & Foreign matter & NMT 2 & 0.4 & NMT 2 & 0.6 & NMT 2 & 0.5 & NMT 2 & 0.2 & NMT 2 & 0.2 \\
\hline 2 & Total ash & NMT 16 & 7.20 & NMT 7 & 2.80 & NMT 22 & 5.52 & NMT 10 & 6.62 & NMT 6 & 2.24 \\
\hline 3 & $\begin{array}{l}\text { Acid insoluble } \\
\text { ash }\end{array}$ & NMT 7 & 2 & NMT 1 & 0.5 & NMT11 & 3 & NMT 1 & 0.6 & NMT 1 & 0.4 \\
\hline 4 & $\begin{array}{l}\text { Water soluble } \\
\text { Extractive }\end{array}$ & NLT 13 & 17.92 & NLT 20 & 40 & NLT 15 & 27 & NLT 19 & 22.5 & NLT 10 & 12.6 \\
\hline 5 & $\begin{array}{l}\text { Alcohol soluble } \\
\text { Extractive }\end{array}$ & NLT 3 & 8 & NLT 10 & 13 & NLT 5 & 8 & NLT 13 & 15.2 & NLT 10 & 14.3 \\
\hline 6 & LOD \% & $<5$ & 4.1 & $<5$ & 4.3 & $<5$ & 3.5 & $<5$ & 3.8 & $<5$ & 3.6 \\
\hline 7.a & $\begin{array}{c}\text { Microbial-TVC } \\
\text { (CFU/g) }\end{array}$ & $1 \times 10^{5}$ & 110 & $1 \times 10^{5}$ & 124 & $1 \times 10^{5}$ & 98 & $1 \times 10^{5}$ & 85 & $1 \times 10^{5}$ & 90 \\
\hline $\mathrm{b}$ & $\begin{array}{c}\text { Total Yeast \& } \\
\text { Mould (CFU/g) }\end{array}$ & $1 \times 10^{3}$ & 10 & $1 \times 10^{3}$ & 12 & $1 \times 10^{3}$ & 14 & $1 \times 10^{3}$ & 11 & $1 \times 10^{3}$ & 15 \\
\hline c & E. coli & Absent & $\mathrm{Ab}$ & Absent & $\mathrm{Ab}$ & Absent & $\mathrm{Ab}$ & Absent & $\mathrm{Ab}$ & Absent & $\mathrm{Ab}$ \\
\hline $\mathrm{d}$ & Salmonella. sp & Absent & $\mathrm{Ab}$ & Absent & $\mathrm{Ab}$ & Absent & $\mathrm{Ab}$ & Absent & $\mathrm{Ab}$ & Absent & $\mathrm{Ab}$ \\
\hline $\mathrm{e}$ & S. aureus & Absent & $\mathrm{Ab}$ & Absent & $\mathrm{Ab}$ & Absent & $\mathrm{Ab}$ & Absent & $\mathrm{Ab}$ & Absent & $\mathrm{Ab}$ \\
\hline $\mathrm{f}$ & Pseudomonas. sp & Absent & $\mathrm{Ab}$ & Absent & $\mathrm{Ab}$ & Absent & $\mathrm{Ab}$ & Absent & $\mathrm{Ab}$ & Absent & $\mathrm{Ab}$ \\
\hline
\end{tabular}


Table 2: Pre-formulation parameters of individual raw materials

\begin{tabular}{|c|c|c|c|c|c|c|}
\hline S. No & Specification & Phyllanthus amarus & Picrorhiza kurroa & Eclipta alba & Azadirachta indica & Swertia chirayita \\
\hline 1 & Texture & Fine powder & Fine powder & Fine powder & Fine powder & Fine powder \\
\hline 2 & Color & Light Brown & Dusty grey & Dark green & Greenish & Light brown \\
\hline 3 & Odor & Indistinct & Indistinct & Indistinct & Indistinct & Indistinct \\
\hline 4 & Taste & Bitter & Bitter & Slightly Bitter & Bitter & Bitter \\
\hline 6 & Shape & Fragment cork cells & Aseptate fibres & Numerous fibres & Slender fibres & Broken fibres \\
\hline 7 & Under UV light & Greenish & Greenish & Greenish & Greenish & Greenish \\
\hline 8 & $10 \% \mathrm{NaOH}$ & Greenish brown & Greenish brown & Greenish brown & Greenish brown & Greenish brown \\
\hline 9 & $5 \% \mathrm{HCl}$ & Greenish yellow & Greenish yellow & Greenish yellow & Greenish yellow & Greenish yellow \\
\hline 10 & $\begin{array}{l}\text { Angle of } \\
\text { Repose }\end{array}$ & 31.2 & 33.4 & 34.3 & 30.5 & 35.8 \\
\hline 12 & $\begin{array}{l}\text { Tap density } \\
\text { (Df) }\end{array}$ & 1.06 & 1.03 & 1.02 & 1.05 & 1.04 \\
\hline 13 & Hausner ratio & 1.15 & 1.17 & 1.08 & 1.10 & 1.08 \\
\hline 14 & Carr`s index & 13.20 & 14.56 & 7.84 & 9.52 & 7.69 \\
\hline
\end{tabular}

Table 3: Organoleptic characters of polyherbal capsule - Liverem.

\begin{tabular}{|c|c|c|c|c|c|}
\hline S.No & Characteristics & Batch: $\mathbf{0 9 0 0 8}$ & Batch: 10009 & Batch: 11010 & Average \\
\hline 1 & Texture & Fine powder & Fine powder & Fine powder \\
\hline 2 & Color & Greenish brown & Greenish brown & Greenish brown \\
\hline 3 & Odor & Indistinct & Indistinct & Indistinct \\
\hline 4 & Taste & Bitter & Bitter & Bitter \\
\hline 5 & pH (5\%) & 6.65 & 6.61 & 6.90 \\
\hline 6 & Under UV light & Greenish brown & Greenish brown & Greenish brown \\
\hline
\end{tabular}

Table 4: Quality control parameters for polyherbal capsule - Liverem.

\begin{tabular}{|c|c|c|c|c|c|}
\hline S. No & Characteristics & Batch: 09008 & Batch: 10009 & Batch: 11010 & Average \\
\hline 1 & Weight variation & Within IP limit & Within IP limit & Within IP limit & Within IP limit \\
\hline 2 & Moisture analysis \% & 3.5 & 3.6 & 4.0 & 3.7 \\
\hline 3 & Drug content & Within IP limit & Within IP limit & Within IP limit & Within IP limit \\
\hline 4 & Disintegration (Sec) & 240.11 & 240.16 & 240.22 & 240.16 \\
\hline 5 & Angle of Repose $\left(^{\circ}\right)$ & 32.6 & 33.1 & 32.8 & 32.83 \\
\hline 6 & Bulk Density $\left(\mathrm{g} / \mathrm{cm}^{3}\right)$ & 0.96 & 0.94 & 0.95 & 0.95 \\
\hline 7 & Tap density $\left(\mathrm{g} / \mathrm{cm}^{3}\right)$ & 1.04 & 1.02 & 1.04 & 1.03 \\
\hline 8 & Hausner ratio & 1.08 & 1.08 & 1.09 & 1.08 \\
\hline 9 & Carr's index & 7.69 & 7.84 & 8.65 & 8.07 \\
\hline
\end{tabular}

cadmium [24 -26]. Limits for cadmium level in ASU products are less than $0.3 \mathrm{ppm}$.

Arsenic is one of WHO`s ten chemicals of major public health. Arsenic occurs in two forms inorganic and organic. Inorganic arsenic such as arsenic trioxide, arsenic pentoxide and sodium arsenate which is found in water and is highly toxic, while organic arsenic such as monomethylarsonic acid, dimethylarsonic acid and arsenobetamine probably found in sea foods are less harmful to health. Acute effect of arsenic is vomiting, abdominal pain and diarrhoea. Long term effects are skin pigmentation, changes on the palms and soles of feet which also lead to skin, bladder and lung cancers [27]. Permissible limits in ASU products are 03ppm. People generally exposed to methyl mercury through intake of sea foods. Mercury exists in various forms elemental (e.g. methylmercury). These forms of mercury differ in their degree 
Table 5: Microbial and Heavy metal analysis of polyherbal capsule - Liverem.

\begin{tabular}{|c|c|c|c|c|c|}
\hline S. No & Characteristics & Batch: 09008 & Batch: 10009 & Batch: 11010 & Average \\
\hline \multicolumn{6}{|c|}{ Microbial limits } \\
\hline 1 & Total Bacterial count & $<100 \mathrm{cfu} / \mathrm{g}$ & $<100 \mathrm{cfu} / \mathrm{g}$ & $<100 \mathrm{cfu} / \mathrm{g}$ & $<100 \mathrm{cfu} / \mathrm{g}$ \\
\hline 2 & Total Yeast \& Mould & $<10 \mathrm{cfu} / \mathrm{g}$ & $<10 \mathrm{cfu} / \mathrm{g}$ & $<10 \mathrm{cfu} / \mathrm{g}$ & $<10 \mathrm{cfu} / \mathrm{g}$ \\
\hline 3 & Escherichia coli & Absent & Absent & Absent & Absent \\
\hline 4 & Salmonella $s p$ & Absent & Absent & Absent & Absent \\
\hline 5 & Staphylococcus & Absent & Absent & Absent & Absent \\
\hline 6 & Pseudomonas & Absent & Absent & Absent & Absent \\
\hline \multicolumn{6}{|c|}{ Test for Heavy metals } \\
\hline A & Mercury (1 ppm) & Within limits & Within limits & Within limits & Within limits \\
\hline $\mathrm{B}$ & Lead (10 ppm) & Within limits & Within limits & Within limits & Within limits \\
\hline $\mathrm{C}$ & Cadmium (0.3 ppm) & Within limits & Within limits & Within limits & Within limits \\
\hline
\end{tabular}

of toxicity and in their effects on nervous, digestive and immune systems and on lungs, kidney and eyes. $01 \mathrm{ppm}$ is permissible limit for ASU products. The primary health effect of methylmercury is impairment of neurological development of foetus. Chronic exposure to mercury shows cognitive impairment, central and peripheral nervous system toxicities [28]. The formulation was checked for the presence of heavy metal contents namely $\mathrm{Pb}, \mathrm{Cd}$, As, $\mathrm{Hg}$ and the results are shown in Table 5. None of the heavy metals was found to exceed their respective permitted level in the formulation.

\section{Conclusion}

Analytical approaches for the polyherbal formulation standardization is likely to be helpful for quality manufacturing and supply of herbal drugs to the needy people around the globe. Conclusively, present study has become a scientific evidence for the development of quality control parameters and Liverem-a hepatoprotective polyherbal formulation has passed all the criteria. Further research on marker compounds analysis, toxicological studies and clinical trials are in progress.

\section{Acknowledgement}

The author expressing thanks to Head, R\&D Centre, Rumi Herbals Pvt Ltd for allowed doing the research work.

\section{References}

1. Pasumarthi Phaneendra, Rupesh Kumar M, Surendra Bodhanapu, Tamizmani T. Hepatoprotective herbs: an overview. Int J of Pharm Res \& Dev. 2011;3(3):105-111.

2. Kuruvilla A. Herbal Formulation as Pharmacotherapeutic agents. Indian J of Exp Biol. 2002;40:7-11.

3. Thyagarajan SP, Jayaram S, Gopalakrishnan V, Hari R, Jeyakumar P, Sripathi MS, et al. Herbal medicines for liver diseases in India. J Gastroenterol Hepatol. 2002;17 Suppl 3:S370-6.

4. Waldesch FG, Konigswinth BS, Remagen HB. Herbal Medicinal products scientific and Regulatory basis for development quality assurance and marketing. Washington DC: Medpharm stuttagart and CRC press; 2003.p:37-52.
5. Sharma AK, Gaurav SS, Balkrishna A. A rapid and simple scheme for the standardization of polyherbal drugs. Int J Green Pharm. 2009;3:134140

6. Ahmad I, Aqil F, Owais M. Turning medicinal plants into drugs. Mod Phytomed. 2006;384:67-72.

7. The Ayurvedic Pharmacopeia of India, Department of AYUSH, Govt. of India.

8. The Siddha Pharmacopeia of India, Department of AYUSH, Govt. of India.

9. World Health Organization. Quality control methods for medicinal plant materials, WHO press. 2011.

10. Lohar DR. Protocol for testing Ayurvedic, Siddha \& Unani Medicines. Pharmacopoeial Laboratory for Indian Medicines, Dept. of AYUSH, GOVT. of India). 2007.

11. Carr RL. Evaluating flow properties of solids. Chem. Eng. 1965;72:163168.

12. Lachman L, Liebermann HA and Kanig JL. Theory and Practice of Industrial Pharmacy. Mumbai, India:Varghese Publishing House. 1986.

13. Indian Pharmacopeia. Indian Pharmacopeia Commission. Govt of India. 2007.

14. Ramaiah M, Chakravathi G, Yasaswini K. In vitro biological standardization, formulation and evaluation of directly compressed polyherbal anthelmintic tablets. Pharmacog J. 2013:1004.

15. Allen Jr LV. The art, Science, and Technology of Pharmaceutical Compounding. Edition 3. Washington DC: American Pharmacists Association; 2008;402.

16. Choudhary N, Sekhon BS. An overview of advances in the standardization of herbal drugs. J Pharm Educ Res. 2011;2(2):55-70.

17. Beaubrum G, Gray GE. A review of herbal medicines for psychiatric disorders. Psychiatr Serv. 2000;51:1130-1134.

18. Chawla S, Sharma AK, Handa SS, Dhar KL. Chemical Investigation and anti-inflammatory activity of Vitex negundo seeds: Part I. Indian J chem. 1991;30:773-776.

19. Shyamala devi CS, Srinivasan P. Role of Liverem, a polyherbal formulation of enzymatic antioxidant status in $\mathrm{CCl}_{4}$ induced 
hepatotoxicity, International conference on Natural Antioxidants and free Radicals in Human Health. Radiation biology. Bombay. 2003.

20.Anonymous, Indian Herbal Pharmacopeia. Vol. I. Indian Drug Manufacturer Association. Mumbai. 2002.

21. Chui SH, Wong YH, Chio HI, Fong MY, Chiu YM, Szeto YT, et al. Study of heavy metal poisoning in frequent users of Chinese medicines in Hong Kong and Macau. Phytother Res. 2013;27(6):859-63. doi: 10.1002/ ptr.4816.

22. Johnson FM. The genetic effects of environmental lead, Mutation Research. Reviews in Mutation Res. 1998;410(2):123-140.

23. Agency for Toxic Substances and Disease Registry (ATSDR) Toxicological Profile for Lead (Update). Public Health Service, U.S. Department of Health and Human Services: Atlanta, Ga, USA. 2007.
24. Li SM, Y Ning HM, Wu XY. Heavy metals in Chinese therapeutic foods and herbs. J. of the Chem. Society of Pakistan. 2012;34(5):1091-1095.

25. Martin S, Griswold W. Human health effects of heavy metals in Environmental Science and Technology Briefs for Citizens, Centre for Hazardous Substance Research. Manhattan. Kan. USA. 2009;15:1-6.

26. Maobe MAG, Gatebe E, Gitu L, Rotich H. Profile of heavy metals in selected medicinal plants used for the treatment of diabetes, malaria and pneumonia in Kisii Region southwest Kenya. Global J of Pharmacol. 2012;6(3):245- 251.

27. Flanagan SV, Johnston RB, Zheng Y. Arsenic in tube well water in Bangladesh: health and economic impacts and implications for arsenic mitigation. Bull World Health Organ. 2012;90:839-846.

28. WHO, Media centre. Mercury and health fact sheet. January 2016. 